\title{
Imidazolium-Based Ionic Liquids: Some Research Methods, Applications and Physico-Chemical Properties
}

\author{
(10) Renato Tomaš
}

\author{
University of Split, Faculty of Chemistry and Technology, Department of Physical Chemistry, Ruđera Boškovića 35, HR-21000 Split, Croatia \\ 区■r rtomas@ktf-split.hr
}

RECEIVED: October 26, 2021 * REVISED: December 6, 2021 * ACCEPTED: December 6, 2021

THIS PAPER IS DEDICATED TO MY WIFE ANITA AND TO MY SONS PETAR AND LOVRE

\begin{abstract}
Imidazolium-based ionic liquids (ILs) represent a well-studied class of ILs. These compounds are characterized by many fascinating properties such as non-flammability, low vapor pressure, wide electrochemical window, and thermodynamic and kinetic stability. This review paper aims to provide an insight into some experimental methods of investigations and applications of these ILs. Additionally, some results on the topic of imidazolium-based ILs in various solvents are presented.
\end{abstract}

Keywords: imidazolium-based ionic liquids, water, organic solvents, application of ionic liquids, physico-chemical properties.

\section{INTRODUCTION}

ONIC LIQUIDS (ILS) in principle are a diverse group of salts which are liquid at ambient temperatures. The chemistry of ILs dates back to 1914, when Paul Walden synthesized the first IL ethylammonium nitrate, $\left[\mathrm{EtNH}_{3}\right]\left[\mathrm{NO}_{3}\right]$, with a melting point of $12{ }^{\circ} \mathrm{C} .[1,2]$ In 1982 John Wilkes et al. introduced tetrachloroaluminate ILs based on 1-alkyl-3methylimidazolium as cation. ${ }^{[3,4]}$ The water and air-sensitivity of these substances led to what can be termed the second generation of ILs when in 1992 the groups of Seddon, Husey, and Chauvin suggested air- and water-stable ILS through the replacement of moisture-sensitive $\mathrm{AlCl}_{4}^{-}$anion by $\mathrm{BF}_{4}^{-}$and other anions (hydrolytically stable anions or conjugated bases of weak acids). ${ }^{[5]}$ From 1998, Jim Davis and others introduced the $3^{\text {rd }}$ generation which sometimes is featured in literature under the term "designer solvents“ or "task-specific ILs".[6] ILs are mostly liquid salts at ambient temperature composed purely of cations and anions. ${ }^{[2]}$ The IL cation is generally an organic structure of low symmetry. Based on the cation, ILs may be divided into 6 groups: fivemembered heterocyclic cations, six-membered and benzofused heterocyclic cations, ammonium, phosphonium and sulphonium based cations, functionalized imidazolium cations and chiral cations. The anions of ILs include halides, hydrogen sulfate, tetraflouroborate, hexaflourophosphate, alkylsulphates, alkylphosphates, mesylate, acetate, borates, carboranes, etc.

Many existing scientific programmes elucidate the importance of ILs (e.g. EXIL - ExChange on lonic Liquid, from European Cooperation in Science in Technology CM1206, 2013-2017., labs (e.g. Catholic University of Leuven, Belgium), an industry that produces only ILs (e.g. IoLiTec company, Germany). Over recent years, ILs have gained importance due to their unique physical and chemical ptoperties, causing a growing number of scientists and engineers to investigate possible application for these liquids. Their outstanding advantages make them interesting for many applications and offer great potential for inovations. The properties of ILs such as high termal stability, low vapour pressure, electroactivity, nonflammability and exstensive liquid range, anti-microbial properties, unusual solvation properties, highly tunable properties by cation and anion variation and combination promote them as "green" solvents. [7] Therefore, ILs are not only interesting for the scientific community, but have

(cc) Br 
industrial application as well. The importance of ILs for the scientific community is also evident through the number of recently published scientific articles. Thus, according to the Web of Science database, only for imidazolium-based ILs for a period from 2017 to today, about 1400 papers have been published (see Figure 1).

Furthermore, M. Bešter-Rogač in their study, ${ }^{[8]}$ asked one intersting question, whether ILs are simple or complex electrolytes. In that paper, M. Bešter-Rogač discussed the similarities and differences between common "classical" eletrolytes and common surfactants and ILs and the surface-active ILs to stress their significance and point out on their weak points. The conclusion is that ILs are complex in their pure state, where the structure is strongly dependent on the structures of cations and anions enabling and/or hindering the packaging and/or arrangement of IL molecules. In solutions, ILs behave like simple or classical electrolytes and/or common or classical surfactants, thus sharing the "complexity" of electrolyte solutions. But also in solutions, the structure of the ions play a significant role due to the possibility of diverse ion-ion and ion-solvent interactions. ILs can serve as an excellent model for studying ionic interactions, hydrophobic effect, and specific ion effect to help expand the knowledge on electrolyte and surfactant aqueous and non-aqueous solutions.

This review paper examines some experimental methods, applications, and recent results for imidazoliumbased ILs (see Figure 2.) in various solvents.

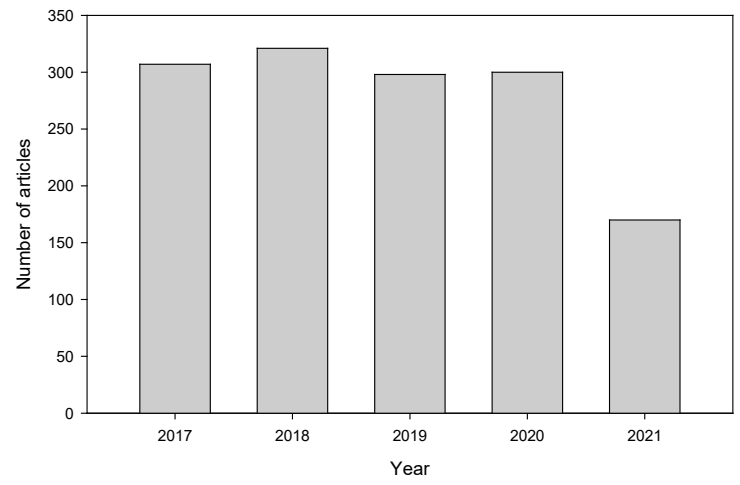

Figure 1. Number of articles described the imidazoliumbased ILs found from Web of Science, in the period 2017 today.

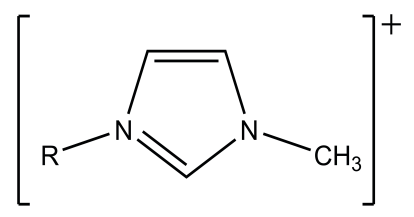

Figure 2. A general scheme of 1-alkyl-3-methylimidazolium cation (alkyl, R: methyl, ethyl, butyl, hexyl, octyl, etc.).

\section{EXPERIMENTAL SETUP FOR SOME EXPERIMENTAL METHODS AND CALCULATIONS}

Physico-chemical studies of ILs in water and organic solvents play a very important role in understanding the solute-solute, solute-solvent, and solvent-solvent interactions in solutions. The chemical constitution of ILs determines the nature of intramolecular and intermolecular interactions and thus the macroscopically observable properties such as thermodynamic and transport properties. Estimating solute-solvent interactions can be obtained thermodynamically and from the measurements of partial molar volumes, viscosity $B$-coefficient, and conductivity studies. Namely, studies of transport properties of ILs, along with thermodynamic studies, give very valuable information about various interactions in solutions. ${ }^{[9]}$ The changes in ionic solvation have important applications in such diverse areas as organic and inorganic synthesis, studies of reaction mechanisms, non-aqueous battery technology, extraction, environmental protection, etc.

\section{Conductivity and Ion Association}

Conductometry is an electroanalytical method of obtaining analytical and physicochemical information by measuring the conductivities of electrolyte solutions. ${ }^{\left[{ }^{[-11]}\right.}$ For conductance measurements is usually used a highly precise conductance bridge (Leeds \& Northrup), ${ }^{[12]}$ or RLC WaynerKerr $6430 \mathrm{~B}$ conductivity meter, ${ }^{[13]}$ equipment with a threeelectrode cell. The uncertainty for this measurement is $0.02 \%$. Namely, the temperature and concentration dependence of the electrical conductivity of electrolyte solutions has been proved as one of the most appropiate methods for studyng ion-ion, ion-solvent, and solventsolvent interactions in solutions. In this paragraph, more attention will be dedicated to the low concentration chemical model (ICCM), ${ }^{[14]}$ which turned out as very successful for the analysis of the association reaction of the symmetrical electrolytes (IL) in aqueous and non-aqueous solutions.

Therefore, experimental conductivity data for ILs in water (W) or organic solvents (S) can be analysed using equation (1) according to the IcCM model. This approach used the following set of equations:

$\Lambda_{m}=\alpha\left[\Lambda^{\circ}-S(\alpha c)^{1 / 2}+E(\alpha c) \ln (\alpha c)+J(\alpha c)+J_{3 / 2}(\alpha c)^{3 / 2}\right]$

together with the equation

$$
K_{A}=\frac{1-\alpha}{\alpha^{2} c y_{ \pm}^{2}}
$$

and equation 


$$
\ln y_{ \pm}=-\frac{A \alpha^{1 / 2} c^{1 / 2}}{1+B R \alpha^{1 / 2} c^{1 / 2}}
$$

In these equations $\Lambda_{m}$ and $\Lambda^{\circ}$ is the molar conductivity and limiting molar conductivity, respectively, $\alpha$ is the dissociation degree of the electrolyte (IL), $K_{\mathrm{A}}$ is the ionic association constant, $r$ is the distance parameter of the ions, $y_{ \pm}$is the activity coefficient of ions on the molar scale, while $A$ and $B$ are the coefficients of the DebyeHückel equation. Meaning of $S, E, J$ and $J_{3 / 2}$ is described in Refs. ${ }^{[14-16]}$.The values of $\Lambda^{\circ}$ can be obtained using computational procedure given by Fuoss ${ }^{[17,18]}$ assuming it is $R=q$ (Bjerrum distance). ${ }^{[14]}$

Further, additional information on the ion-solvent interaction is also provided by analysing changes in the value of the Walden product $\left(\Lambda^{\circ} \eta\right) ; \eta$ is solvent viscosity. ${ }^{[19,20]}$ From the temperature dependence of the association constant we can calculate the free energy of Gibbs, and entropy and enthalpy of ion association.

\section{Volumetric Properties}

Today, for measurement of densities, $d$, of solvent or solution, is used a fully automated DMA 5000 Anton-Paar apparatus with a measurements accuracy of $\pm 5 \times 10^{-6} \mathrm{~g} \mathrm{~cm}^{-3}$ and repeatability of $\pm 10^{-6} \mathrm{~g} \mathrm{~cm}^{-3}$.

The apparent molar volumes, $V_{\Phi}$, can be calculated from the densities of solutions using the following equation:

$$
V_{\Phi}=\frac{1000\left(d_{0}-d\right)}{m d d_{0}}+\frac{M}{d}
$$

where $m$ is the molality of solution, $d_{0}$ and $d$ are the density of solvent and solution, while $M$ is the molar mass of solute. Using the values of $V_{\Phi}$, the apparent molar volume at infinite dilution, $V_{\Phi}^{0}$, can be derived applying Masson's equation ${ }^{[9,21,22]}$

$$
V_{\Phi}=V_{\Phi}^{0}+S_{V} \cdot \sqrt{c}
$$

which can be used up to the concentation of $0.1 \mathrm{~mol} \mathrm{dm}^{-3}$ for some ILs. In Eq. (5) $S_{V}$ denoted Masson's interaction coefficient. The concentration dependences of the calculated $V_{\Phi}$ values were also correlated using the Redlich and Meyer ${ }^{[23-25]}$ equation (valid up to the concentration of $0.5 \mathrm{~mol} \mathrm{dm}^{-3}$ ):

$$
V_{\Phi}=V_{\Phi}^{0}+S_{V} \cdot \sqrt{c}+b_{V} \cdot c
$$

where $b_{v}$ is an empirical parameter, and $S_{V}$ is defined as

$$
S_{V}=A_{V}\left(\frac{1}{2} \sum_{i} v_{i} z_{i}^{2}\right)^{3 / 2}
$$

where $v_{\mathrm{i}}$ and $z_{\mathrm{i}}$ are the stoichiometric number and absolute charge of ion i in solute (IL), respectively. The Debye-Hückel limiting slope for the apparent molar volume is identified as $A_{v}$. This value for each solvent can be found in the literature. ${ }^{[26]}$

On the basis of temperature, $T$, dependence of solution density, it can be calculated the thermal expansion coefficient, $\alpha_{p}$, at atmospheric pressure by the following equation:

$$
\alpha_{p}=-\frac{1}{d}\left(\frac{\partial d}{\partial T}\right)_{p}
$$

Further, temperature dependence of $V_{\Phi}^{0}$ can be described by a second-order polynomial function:

$$
V_{\Phi}^{0}=c_{0}+c_{1} T+c_{2} T^{2}
$$

where $c_{0}, c_{1}$, and $c_{2}$ are fitted coefficients. The temperaturedependent limiting apparent molar expansibility, $E_{\Phi}^{0}$, can be obtained by differentiating Equation (9)

$$
E_{\Phi}^{0}=\left(\frac{\partial V_{\Phi}^{0}}{\partial T}\right)_{p}=c_{1}+2 c_{2} T
$$

From Eq. (10) follows expresion for Heppler's coefficient ${ }^{[27]}$

$$
\left(\frac{\partial E_{\Phi}^{0}}{\partial T}\right)_{p}=\left(\frac{\partial^{2} V_{\Phi}^{0}}{\partial T^{2}}\right)_{p}=2 c_{2}
$$

According to the values of Heppler's coefficients, ILs can be divided into 3 groups:

a) Structure-breaker (chaotrope) with negative Heppler's coefficient,

b) Structure-makers (kosmotrope) with positive Heppler's coefficient,

c) Borderline with Heppler's coefficient around zero.

Namely, ions that have strong interactions with water molecules can increase the structuring of water, called "order-makers" (kosmotropes). Other ions that decrease the structuring of water are "disorder-makers" (chaotropes). Kosmotropes are usually small and highly charged, while chaotropes are large and low charged. In fact, all multivalent ions are highly hydrated and are, therefore, kosmotropic. ${ }^{[28]}$

\section{Viscosity B-coefficient}

Viscosity, one of the most important transport properties can be used for the determination of solute (IL)-solvent (S) interactions, structures of electrolytic solution and solvation. ${ }^{[9]}$ For measure of viscosity of the solvent and solution is used micro Ubbelohde viscometers and an automatic flow time measuring system ViscoSystem AVS 370 . The errors from calibration and temperature control yielded an uncertainty $<0.1 \%$ of absolute viscosity. The concentration dependence of the relative viscosity, $\eta_{r}$, of electrolyte 
solutions is described by the Jones and Dole, ${ }^{[29-31]}$

$$
\eta_{r}=\eta / \eta_{0}=1+A c^{1 / 2}+B c
$$

where $\eta$ and $\eta_{0}$ are the viscosities of the solution and solvent, respectively. At higher concentration $(c>0.5 \mathrm{~mol}$ $\mathrm{dm}^{-3}$ ) a quadratic term $D c^{2}$ is added in Eq. (12). ${ }^{[32]}$ The viscosity $A$-coefficient measure long-range ion-ion interactions, and the viscosity $B$-coefficient depends on ionsolvent ineractions. If the limiting molar conductivities of the ions are known, $A$-coefficient can be calculated from the ionic interaction theory by Falkenhagen and Vernon ${ }^{[30]}$ using next relation:

$$
A=\frac{0.2577 \Lambda^{0}}{\eta_{0}\left(\varepsilon_{r} T\right)^{1 / 2} \lambda_{+}^{0} \lambda_{-}^{0}}\left[1-0.6863\left(\frac{\lambda_{+}^{0}-\lambda_{-}^{0}}{\Lambda^{0}}\right)^{2}\right]
$$

where $\varepsilon_{\mathrm{r}}$ and $\eta_{0}$ are relative permittivity and viscosity of the solvent at temperature, $T_{;} \Lambda^{0}, \lambda_{+}^{0}$ and $\lambda_{-}^{0}$ are limiting molar conductivities of solute (ILS), imidazolium cation and anion of ILs respectively at constant temperature. R. Tomaš et al. $^{[31]}$ proposed the rearranged Jones-Dole equation in the next form:

$$
\left(\eta_{r}-1\right)-A \cdot c^{1 / 2}=B \cdot C
$$

Eq. (14) represents linear dependence; from the slopes of straight line, viscosity $B$-coefficient can be estimated. Positive values of the $B$-coefficient indicate strong interactions between ions of ILs and solvent. Finally, regarding the temperature coefficients $\mathrm{d} A / \mathrm{d} T$ and $\mathrm{d} B / \mathrm{d} T:[32]$

a) $\mathrm{d} A / \mathrm{d} T>0$, always.

b) $\mathrm{d} B / \mathrm{d} T>$ or $<0$ or $=0$; If $\mathrm{d} B / \mathrm{d} T$ is negative, it shows structure-making nature of this IL.

In addition to the above mentioned experimental methods, some others are cited in the literature, such as dielectric spectroscopy, vapor pressure osmometry, speed of sound, etc. Also, the solvation properties of imidazoliumbased ILs in each solvent can be additionally investigated by molecular dynamic (MD) simulation. Namely, the MD simulations can be used as a powerful tool to beter understand the organization of solvent around ILS and correlate experimental findings. ${ }^{[22]}$

\section{SOME APPLICATIONS OF IMIDAZOLIUM-BASED IONIC LIQUIDS}

\section{Supramolecular Ionic Liquid Gells}

A. Maršavelski et al. ${ }^{[33]}$ prepared supramolecular ionogel by the gelation of room temperature IL 1-butyl-3-methylimidazolium tetrafluoroborate $\left([\mathrm{bmim}]\left[\mathrm{BF}_{4}\right]\right)$ with $(S, S)$-bis(leucinol)oxalamide. The ionic conductivity of solutions and ionogels with low gelator concentrations is higher than that of neat 1-butyl-3-methylimidazolium tetrafluoroborate. The origin of this phenomenon (quantum mechanical calculations) can be attributed to the higher affinity of gelator molecules towards tetrafluoroborate anions, which reduces the electrostatic attractions between $\mathrm{IL}$ ions and thus increases their mobility. For very dense ionogels, decreased ionic conductivity with increasing gelator concentration is less than one order of magnitude relative to neat $[\mathrm{bmim}]\left[\mathrm{BF}_{4}\right]$, and thus they can be classified as highly conductive materials with strong potential for application as functional electrolytes.

Supramolecular ionogels composed of an IL immobilized in a network of self-assembled low-molecular weight molecules have been attracting interst due to their applicability as smart electrolytes for various electrochemical applications. ${ }^{\left[{ }^{[4]}\right.}$ In this article authors report on a series of novel ionogels of imidazolium action of ILs with tetrafluoroborate and bis(trifluoromethylsulfonyl) imide as anions of ILs. So from prepared ionogels, 1-butyl-3-methylimidazolium bis(trifluoromethylsulfonyl)imide prepared with 1 mass per cent (S,S)-bis(phenylalaninol)oxamide, exhbits the best performance: optical transparency, stability over a wide temperature range, high conductivity, and high mechanical strength.

\section{Ionic Liquids as Safe Electrolyte}

Major problem of litium-ion batteries with conventional volatile organic compounds is that short-circuit currents may lead to overheating and ignition of the organic solvents. Imidazolium-based ILs have large electrochemical stabilities and high thermal stability. J.-K. Kim et al.[35] investigated 3-methy-1-propyimidazolium bis(trifluoromethysulfony)imide compelxed with lithium bis(trifluoromethysulfony)imide at molar ratio $1: 1$ as potential electrolyte for lithium batteries. This electrolyte shows a high ionic conductivity $\left(\cong 1.2 \times 10^{-3} \mathrm{~S} \mathrm{~cm}^{-1}\right)$. Electrochemical stability of a series of alkyl methylimidazolium-based ILs for their use as lithium battery electrolytes were invesigated. The oxidation and reduction potentials of the constituent cation and anion of each IL with respect to a $\mathrm{Li}^{+} / \mathrm{Li}$ reference electrode were calculated using density functional theory following the method of thermodynamic cycles, and the electrochemical stability windows of these ILs. The effect of varying the length of alkyl side chain of the methylimidazolium-based cations on the redox potentials and electrochemical stability windows was also investigated. The main conclusion of this investigation is that ILS with $\left[\mathrm{PF}_{6}\right]^{-}$anion have a wider electrochemical stability window. ${ }^{[36]}$ Y. Chai et al. ${ }^{[37]}$ designed new multifunctional 1-(3-amino-3-oxopropyl)-3-vinylimidazolium bis(trifluoromethylsulfonyl)amide. Due to its multifunctional groups, this IL has the potential to improve silicon based lithium 
batteries. The basic group binds water and thereby keeps the formation of hydrogen fluoride at a low level. The vinyl group of the IL contributes to the formation of a uniform passivating solid electrolyte interphase film in a siliconbased lithium ion batteries. Key parameters for lithiumoxygen battery electrolytes ${ }^{[38]}$ such thermal stability, good ionic conductivity, viscosity, potential window, and lithium solvation, possess ILs based on imidazolium cation.

\section{Ionic Liquids in Supercapacitors and Fuel Cell Applications}

Supercapacitors are nowadays considered to be one of the most important electrochemical storage devices. These devices display high power and extraordinary cycle life, and they are currently used in an increasing number of applications. Namely, A. Brandt et al. ${ }^{[39]}$ in his work ilustrate the contributions imidazolium-based ILs might play in the development of high energy, safe, and environmentally friendly supercapacitors. The use of IL based on 1-buthyl-3methylimidazolium cation as electrolytes in an activated carbon/poly(3-methylthiophene) hybrid supercapacitor was investigated by A. Balducci et al. ${ }^{[40]}$ Generally speaking, materials with conductivity above $20 \mathrm{mS} \mathrm{cm}^{-1}$ as 1-ethyl-3methylimidazolium thio-cyanate and 1-ethyl-3-methylimidazolium dicyanamide are good choice for electrochemical use.

Proton conductivity is an essential property of electrolytes in fuel cells. ${ }^{[41]}$ So T. Yasuda and M. Watanabe investigated protic ILs as proton conductors for nonhumidified intermediate-temperature fuel cells. Protic ILs exhibit proton conductivity and activity in fuel cell electrode reactions, as seen in acidic aqueous solutions and acidic polymer membranes. Typical ILs as 1-methyl-3ethylimidazolium bis(trifluoromethanesulfone)imide exhibit high thermal stability, negligible vapor pressure, and nonflammability. Also, ILs can self-dissociate, thus exhibiting high ionic conductivity. Recently, H. Mohammed et al. ${ }^{[42]}$ synthesized of high temperature proton conductors based on zirconium phosphate and imidazolium-based ILs. This material is evaluated for high temperature proton exchange membrane fuel cells applications operating at $200{ }^{\circ} \mathrm{C}$. Their results show high proton conductivity, enhanced water uptake properties, changes in structure, and exfoliation in zirconium phosphates crystal layers upon the introduction of the IL. The study on fuel cell performance by using alkylimidazole ILs (1-methylimidazolium hydrogensulfate, 1 - $n$-butyl-3-methylimidazolium bromide, 1-n-butyl-3-methylimidazoliumtrifluoroacetate, and 1-n-butyl-3-methylimidazolium hydrogensulfate) as electrolytes for fuel cell are performed. ${ }^{[43]}$ The performance of the fuel cell was measured by voltammetry using hydrogen as a fuel and air as an oxygen source. Fuel cell performance tests show that 1 - $n$-butyl-3-methylimidazoliumtrifluoroacetate is the most effective IL electrolyte.

\section{$\mathrm{CO}_{2}$ Capture in Ionic Liquids}

The emission of greenhouse gases, including $\mathrm{CO}_{2}$, is a serious global issue. Due to their remarkable properties, ILs attracted significant attention as promising alternatives for gas "sweetening“. The capacity of ILs for $\mathrm{CO}_{2}$ absorption lies mainly in the anion- $\mathrm{CO}_{2}$ interaction. Also, ILs can tolerate high temperatures when dissolving $\mathrm{CO}_{2}$ due to the wide liquid range and negligible vapor pressure. ${ }^{[4]}$ For example, 1-alkyl-3-methylimidazolium tetrafluroborate IL, $\left[\mathrm{C}_{\mathrm{n}} \mathrm{mim}\right]\left[\mathrm{BF}_{4}\right]$, was chosen for commercial scale development with $\mathrm{BF}_{4}$ after showing long term stability and good gas evolution rates with negligible loss in capacity of the sorbent after repeated cycles. ${ }^{[45]}[\mathrm{bmim}]\left[\mathrm{PF}_{6}\right]$ impregnated membranes were used for separation of $\mathrm{CO}_{2}$ from $\mathrm{N}_{2}$ with and without doping compounds. ${ }^{[46]}$ The imidazolium class of ILs is most widely investigated and reported in the literature. Initial research on $\mathrm{CO}_{2}$ capture with ILs focused primrily on the phase behavior of $\mathrm{CO}_{2}$ with different physical ILs. Absorption $\mathrm{CO}_{2}$ using conventional imidazolium ILs are based on a physical mechanism (no chemical reaction takes place). The anion is believed to play a key role in the dissolution of $\mathrm{CO}_{2}$, whereas the cation is supposed to have a secondary role. ${ }^{[47]}$

E. Santos et al. ${ }^{[48]}$ prepared supported IL membranes with the acetate based room temperature ILs 1-ethyl-3methylimidazolium acetate, [emim][Ac], 1-butyl-3-methylimidazolium acetate, [bmim][Ac], and the monomer vinylbenzyl trimethylammonium acetate, [Vbtma][Ac] to perform the selective separation of $\mathrm{CO}_{2}$ from $\mathrm{N}_{2}$. They performed experiments in the temperature range of 298333 K. Gas permeability increases with temperature decresase in $\mathrm{CO}_{2} / \mathrm{N}_{2}$ selectivity for all studied ILs. $\mathrm{CO}_{2}$ solubility was evaluated using thermogravimetric techniques.

The work from A. S. Aquino et al., ${ }^{[49]}$ demonstrates that the presence of a nucleophilic group in the catalytic system can enhance its performance by the use of an imidazolium-based IL with halide anion or by mixing a halide co-catalyst with ILs. Namely, they are prepared following ILs: 1-butyl-3-methylimidazolium chloride, [bmim] [Cl], 1-butyl-3-methylimidazolium tetrafluoroborate, $\left[\mathrm{bmim}^{-}\left[\mathrm{BF}_{4}\right]\right.$, 1-butyl-3-methylimidazolium bis(trifluoromethylsulfonyl)imide, [bmim] $\left[\mathrm{Tf}_{2} \mathrm{~N}\right]$, and 1-dimethylbutyl-3-methylimidazolium bis(trifluoromethylsulfonyl)imide, [dmbmim] $\left[\mathrm{Tf}_{2} \mathrm{~N}\right]$. Their results show that the combining of imidazolium-based ILs / fluroalkyl anions and a metal halide compound is a good approach for combining the $\mathrm{CO}_{2}$ capture and conversion. It is shown that catalytic conversion of $\mathrm{CO}_{2}$ to carbonates, the temperature, pressure and reaction time play an important role in the conversion and selectivity. The best results were obtained with the catalytic system [bmim] $\left[\mathrm{Tf}_{2} \mathrm{~N}\right] / \mathrm{ZnBr}_{2}$ at 4.0 MPa of pressure, $383.15 \mathrm{~K}$ of temperature and $6 \mathrm{~h}$ of reaction time. 
C. Wang et al. ${ }^{[50]}$ investigated the effects of imidazolium-based IL structures, types of organic superbases, absorption times, and reaction temperatures on the capture of $\mathrm{CO}_{2}$. Their results show that this integrated IL-superbase system is capable of radpid and reversible capture of about $1 \mathrm{~mol} \mathrm{CO}_{2}$ per mole of IL. Furthermore, the captured $\mathrm{CO}_{2}$ can be readily released by either heating or bubbling $\mathrm{N}_{2}$, and recycled with little loss of its capture capability. This efficient and reversible catch-and-release process using the weak acidity of the $\mathrm{C}-2$ proton in nonvolatile. Imidazolium-based ILs provides a good alternative to the current capture methods that use volatile alkanols, amines, or water.

Currently, solvent-based absorption is know as an effective technology to capture acid gases like $\mathrm{CO}_{2}$. In the paper ${ }^{[51]}$ the constant-volume method is used to determine $\mathrm{CO}_{2}$ solubility in propylene carbonate $(\mathrm{PC})$, imidazoliumbased ILs: 1-butyl-3-methylimidazolium tetrafluoroborate, [bmim] $\left[\mathrm{BF}_{4}\right]$, 1-hexyl-3-methylimidazolium tetrafluoroborate, [hmim] $\left[\mathrm{BF}_{4}\right]$, and 1-octyl-3-methylimidazolium tetrafluroborate, $[0 \mathrm{mim}]\left[\mathrm{BF}_{4}\right]$, and their mixtures at temperature from 313.15 to $333.15 \mathrm{~K}$ under pressures up to about $1 \mathrm{MPa}$. The experimental results illustrate that adding [omim] $\left[\mathrm{BF}_{4}\right.$ ] into $\mathrm{PC}$ can improve the $\mathrm{CO}_{2}$ solubility and the $\mathrm{CO}_{2}$ selectivity compared with the pure $\mathrm{PC}$, which increases with the increasing [omim] $\left[\mathrm{BF}_{4}\right]$ mass fraction in the mixture. Therefore, the mixtures of $\mathrm{PC}$ and [omim] $\left[\mathrm{BF}_{4}\right]$ may be used as promising physical solvent to capture $\mathrm{CO}_{2}$.

L. Zhao et al. ${ }^{[52]}$ in their work synthesized and characterized two kinds of ether-functionalized imidazolium ILs, 1-methoxethyl-3-methylimidazolium hexafluoroborate, [eommim] $\left[\mathrm{BF}_{6}\right]$ and 1-methoxyethyl-3-methylimidazolium bis(trifluoro-methylsulfony)imide, [eommim] $\left[\mathrm{Tf}_{2} \mathrm{~N}\right]$. Solubility values of $\mathrm{CO}_{2}$ in these ILs were determined by isometric weight method at temperature from 298.15 to $343.15 \mathrm{~K}$ and the pressure up to $5.185 \mathrm{MPa}$. Furthermore, solubilities of other flue gases, $\mathrm{N}_{2}$ and $\mathrm{O}_{2}$, in these two ILs were also measured at $303.15 \mathrm{~K}$. It was shown that little influence had been exerted on $\mathrm{CO}_{2}$ solubility by the introducing ether groups on the cation. Still, it decreased $\mathrm{N}_{2}$ and $\mathrm{O}_{2}$ solubility, resulting in the remarkable increase of $\mathrm{CO}_{2} / \mathrm{N}_{2}$ and $\mathrm{CO}_{2} / \mathrm{O}_{2}$ selectivity.

The design of suitable solvent is important to separate $\mathrm{CO}_{2}$ from natural gas. In work, ${ }^{[53]}$ the abilities of ILs 1-buthyl-3-methylimidazolium acetate, [bmim][Ac], 1-butyl-3-methylimidazolium tetrafluoroborate, $[\mathrm{bmim}]\left[\mathrm{BF}_{4}\right]$, and their binary mixtures are experimentally investigated for $\mathrm{CO}_{2}$ separation from $\mathrm{CH}_{4}$.

The high solubility of $\mathrm{CO}_{2}$ in imidazolium-based ILs has been demonstrated in many investigations. ${ }^{[54]}$ For example, Cadena et al. ${ }^{[55]}$ investigated mechanisms for the high affinity between $\mathrm{CO}_{2}$ and imidazolium-based ILs. Namely, experimental and molecular modeling studies are conducted to investigate the underlying mechanisms for the high solubility of $\mathrm{CO}_{2}$ in imidazolium-based ILs. $\mathrm{CO}_{2}$ absorption isotherms at 10,25 and $50^{\circ} \mathrm{C}$ are reported for six different ILs formed by pairing three different anions with two cations that differ only in nature of the "acidic" site at 2-position on the imidazolium ring. Both the experimental and molecular dynamics simultations results indicate that the anion has the most significant impact on the solubility of $\mathrm{CO}_{2}$. Experimentally, it is found that the bis(trifluoromethylsulfonyl)imide anion has the greatest affinity for $\mathrm{CO}_{2}$, while there is little difference in $\mathrm{CO}_{2}$ solubility between ILS having the tetrafluoroborate or hexafluorophosphate anion. The simultations show strong organization of $\mathrm{CO}_{2}$ about hexafluorophosphate anions, but only slight differences in $\mathrm{CO}_{2}$ structure about the different cations.

\section{lonic Liquids as „Green“ Engineering Liquids}

Over the two past decades, ILs have become one of the fastest growing "green“ media for chemists and engineers due to their superb physicochemical properties. ILs with imidazolium ring can be used as heat transfer fluids, azeotrope-breaking liquids, lubricants, electrolytes, liquid crystals, for mercury capture, as solvents for dissoluition and separation, for analysis (GC column stacionary phase), solar thermal conversion, or in biofuel production. ${ }^{[43-46,56-68]}$

In addition, imidazolium-based ILs are also interesting as a medium for examining plant growth and germination. ${ }^{[69-72]}$ Furthermore, Dimitrijević et al. ${ }^{[73]}$ reported and discussed novel phase diagrams for aqueous solutions of 1-alkyl-3-methylimidazolium- and 1-butyl-3-ethylimidazoliumbased ILs combined with phosphate-based salts, namely, $\mathrm{K}_{3} \mathrm{PO}_{4}$ or $\mathrm{K}_{2} \mathrm{HPO}_{4}$. The anion influence on the ability to form aqueous biphasic system ( $\mathrm{ABS}$ ) was investigated for the IL with the same 1-butyl-3-methylimidazolium cation, $\left[\mathrm{bmim}^{+}\right]$, and various anions, for example salicylate, $\left[\mathrm{SAL}^{-}\right]$, trifluoromethanesulfonate, $\left[\mathrm{TFS}^{-}\right]$, dicyanamide, $\left[\mathrm{DCA}^{-}\right]$, and chloride, $\left[\mathrm{Cl}^{-}\right]$. The order of studied anions to form $A B S$ is $\left[\mathrm{TFS}^{-}\right]>\left[\mathrm{SAL}^{-}\right]>\left[\mathrm{DCA}^{-}\right]>\left[\mathrm{Cl}^{-}\right]$. It was shown that 1-hexyl3-methylimidazolium chloride has a better ability to form ABS comparing to IL with butyl chain and the same anion. Also, newly synthesized IL containing ethyl group 1-butyl-3ethylimidazolium bromide was investigated, showing the influence of both ethyl group and bromide anion on the ability of ABS formation. Dimitrijević at al. ${ }^{[74]}$ also reported a simultaneous one-step extraction of five pesticides (acetamiprid, imidaclopride, simazine, linuron and tebufenozide) of different polarity using ABS based on 1-butyl3 (methyl or ethyl) subsituted imidazolium or pyrrolidinium ILs with bromide or dicyanamide anion and potassium carbonate as a salting-out agent. The effect of the cation alkyl chain length and the variation of anions of the IL on 
the ABS formation and the efficiency of pesticide extraction were investigated. Complete extraction of all studied pesticides was obtained applying ABS based on 1-butyl-3-ethylimidazolium dicyanamide. It was shown that simultaneous extraction of the different polarity pesticides is achieved in a single-step procedure applying properly tail and ILs in the ABS formulation. Also, it was found that 1-butyl-3-ethylimidazolium dicyanamide achieves the strongest interactions with the polar pesticides (acetamiprid and imidaclopride) leading to the highest partition coefficients.

\section{SOME RECENT CONDUCTOMETRIC, VOLUMETRIC, AND VISCOMETRIC RESULTS FOR IMIDAZOLIUM-BASED IONIC LIQUIDS IN VARIOUS SOLVENTS}

The values of limiting molar conductivity or molar conductivity at infinite dilution, $\Lambda^{\circ}$, and association constant, $K_{\mathrm{A}}$ for different imidazolium-based ILs in various solvents with different relative permittivity, $\varepsilon_{r}$, are collected in Table 1. Nature of ILs and properties of the solvent can have a significant impact on molar conductivity. For example, for [hmim] [Cl] value of $\Lambda^{\circ}$ follows the order: $\Lambda^{\circ}(\mathrm{MeOH})>\Lambda^{\circ}(\mathrm{W})>\Lambda^{\circ}(\mathrm{EtOH})>\Lambda^{\circ}(1-\mathrm{PrOH})>\Lambda^{\circ}(2-\mathrm{PrOH})>$ $\Lambda^{\circ}(1-\mathrm{BuOH})$, and for $[\mathrm{bmim}]\left[\mathrm{BF}_{4}\right]$ follows next order: $\Lambda^{\circ}(\mathrm{CN})>$ $\Lambda^{\circ}(\mathrm{DCM})>\Lambda^{\circ}(\mathrm{MeOH})>\Lambda^{\circ}(\mathrm{W})>\Lambda^{\circ}(\mathrm{DMF})>\Lambda^{\circ}(\mathrm{DMAC})>$ $\Lambda^{\circ}(\mathrm{DMSO})>\Lambda^{\circ}(1-\mathrm{PrOH})>\Lambda^{\circ}(2-\mathrm{PrOH})>\Lambda^{\circ}(1-\mathrm{BuOH})$. This trend is mainly determined by an opposite trend in solvent viscosity. For solvents viscosity data see Ref. ${ }^{[75]}$. Furthermore, values of $\Lambda^{\circ}$ decrease with increasing alkyl chain length of the imidazolium chloride ILs (from $b$ to $j$ ) in water medium. ${ }^{[76]}$

From Table 1. it can be seen that $K_{\mathrm{A}}$ values for presented ILs are biggest in $\mathrm{DCM},{ }^{[81]} 1-\mathrm{BuOH},{ }^{[75,83]} 1-\mathrm{PrOH},{ }^{[82,83]}$ and 2-PrOH.[75,83] These values indicate that the examined ILs are strongly associated in these solvents. The ion association is moderate in $\mathrm{MeOH},[75,83,84]$ and slight in $A C N,{ }^{[77,79,80]} \mathrm{DMAc}^{[88]}$ and in DMF. ${ }^{[85]}$ Weak ion association is present in DMSO, ${ }^{[86]}$ and in W solvent. ${ }^{[76-78]}$ These results suggest that the imidazolium cation and anions of ILs are less associated or fully disociated in the solvent, which possesses a high relative permittivity due to the independent solvation od ions. One of the important factors affecting the ionic association is the ion-solvent interaction. ${ }^{[86]}$ For example $K_{\mathrm{A}}$ values in ACN follows the order: $K_{\mathrm{A}}[\mathrm{emim}]\left[\mathrm{BF}_{4}\right]>K_{\mathrm{A}}[\mathrm{bmim}]\left[\mathrm{BF}_{4}\right]>K_{\mathrm{A}}[\mathrm{bmim}][\mathrm{Cl}]>$ $K_{\mathrm{A}}$ [emim] $\left[\mathrm{EtSO}_{4}\right]$. If we compare two different solvents, e.g. $\mathrm{ACN}$ and $\mathrm{DCM}$, it can be seen that $K_{\mathrm{A}}$ values are higher for imidazolium-based ILs ( $I$ and $\mathrm{m}$ ) in $\mathrm{ACN}$ in comparision to DCM.

Some research group presents data about the influence of temperature on conductivity; e.g. see Refs. ${ }^{[78,81,85]}$
Table 1. Comparision of the recent values of limiting molar conductivity, $\Lambda^{\circ}$, and association constants, $K_{A}$, for some imidazolium-based ILs in different solvents of relative permittivity, $\varepsilon_{\mathrm{r}}$ at $298.15 \mathrm{~K}$

\begin{tabular}{|c|c|c|c|c|}
\hline Solvent ${ }^{(a)}$ & $\varepsilon_{\mathrm{r}}$ & $\Lambda^{\circ} / \mathrm{S} \mathrm{cm}^{2} \mathrm{~mol}^{-1}$ & $K_{\mathrm{A}} / \mathrm{dm}^{3} \mathrm{~mol}^{-1}$ & Ref. \\
\hline \multirow[t]{12}{*}{ W } & 78.358 [76] & $124.06^{(b)}$ & $4.9^{(b)}$ & {$[76]^{*}$} \\
\hline & & $119.94^{(c)}$ & $2.5^{(c)}$ & $*$ \\
\hline & & $119.13^{(d)}$ & $1.6^{(d)}$ & * \\
\hline & & $115.05^{(\mathrm{e})}$ & $3.1^{(\mathrm{e})}$ & $*$ \\
\hline & & $109.34^{(f)}$ & $5.2^{(f)}$ & $*$ \\
\hline & & $105.07^{(\mathrm{g})}$ & $2.6^{(\mathrm{g})}$ & $*$ \\
\hline & & $102.71^{(h)}$ & $3.8^{(h)}$ & $*$ \\
\hline & & $100.73^{(i)}$ & $3.5^{(i)}$ & $*$ \\
\hline & & $99.90^{(j)}$ & $4.9^{(j)}$ & * \\
\hline & & $84.05^{(k)}$ & $0.008^{(k)}$ & [77] \\
\hline & & $114.27^{(1)}$ & $0.89^{(1)}$ & [78] \\
\hline & & $107.39^{(\mathrm{m})}$ & $0.16^{(\mathrm{m})}$ & [78] \\
\hline \multirow[t]{4}{*}{$\mathrm{ACN}$} & 35.96 [77] & $173.91^{(f)}$ & $63.7^{(f)}$ & [79] \\
\hline & & $173.57^{(k)}$ & $41.2^{(k)}$ & [77] \\
\hline & & 197.10(I) & $15.9^{(1)}$ & [80] \\
\hline & & $189.29^{(m)}$ & $15.7^{(\mathrm{m})}$ & [80] \\
\hline \multirow[t]{3}{*}{$\mathrm{DCM}$} & 8.82 [77] & $28.3^{(k)}$ & $6.6^{(k)}$ & [77] \\
\hline & & $181.07^{(I)}$ & $595.110^{(1)}$ & [81] \\
\hline & & $161.08^{(m)}$ & $478.920^{(\mathrm{m})}$ & [81] \\
\hline \multirow[t]{3}{*}{ 1-PrOH } & 20.45 [75] & $31.426^{(1)}$ & $943^{(1)}$ & [82] \\
\hline & & $30.290^{(\mathrm{m})}$ & $987^{(m)}$ & [82] \\
\hline & & $25.74^{(\mathrm{g})}$ & $352.6^{(\mathrm{g})}$ & [83] \\
\hline \multirow[t]{3}{*}{ 2-PrOH } & $19.45[83]$ & $22.71^{(\mathrm{g})}$ & $790^{(\mathrm{g})}$ & [83] \\
\hline & & $28.285^{(1)}$ & $1662^{(1)}$ & [75] \\
\hline & & $27.881^{(m)}$ & $1780^{(m)}$ & [75] \\
\hline \multirow[t]{3}{*}{$\mathrm{MeOH}$} & 32.63 [75] & $113.15^{(\mathrm{g})}$ & $28.6^{(\mathrm{g})}$ & [83] \\
\hline & & $134.0^{(1)}$ & $66.1^{(I)}$ & [75] \\
\hline & & $121.84^{(\mathrm{m})}$ & $37.7^{(\mathrm{m})}$ & [84] \\
\hline $\mathrm{EtOH}$ & 24.356 [83] & $48.38^{(\mathrm{g})}$ & $90^{(\mathrm{g})}$ & [83] \\
\hline \multirow[t]{2}{*}{ DMF } & $36.81[75]$ & $93.47^{(1)}$ & $11.30^{(1)}$ & [85] \\
\hline & & $89.83^{(\mathrm{m})}$ & $10.57^{(\mathrm{m})}$ & [85] \\
\hline DMSO & $46.52[86]$ & $41.51^{(\mathrm{m})}$ & $4.6^{(\mathrm{m})}$ & [86] \\
\hline \multirow[t]{3}{*}{ 1-BuOH } & 17.33 [83] & $16.77^{(\mathrm{g})}$ & $920^{(\mathrm{g})}$ & [83] \\
\hline & & $20.682^{(1)}$ & $2671^{(I)}$ & [83] \\
\hline & & $20.546^{(\mathrm{m})}$ & $2780^{(m)}$ & [75] \\
\hline \multirow[t]{2}{*}{ DMAc } & 39.11 [87] & $78.33^{(1)}$ & $14.79^{(1)}$ & [88] \\
\hline & & $75.04^{(\mathrm{m})}$ & $10.24^{(\mathrm{m})}$ & \\
\hline
\end{tabular}

(a) W, water; $\mathrm{ACN}$, acetonitrile; $\mathrm{DCM}$, dichloromethane; 1-PrOH, 1-propanol; 2-PrOH, 2-propanol; $\mathrm{MeOH}$, methanol; EtOH, ethanol; DMF, N,N-dimethylformamide; DMSO, dimetylsulfoxide; 1-BuOH, 1-butanol; DMAc, $N, N$-dimethylacetamide

(b) $[\mathrm{mim}][\mathrm{Cl}], 1$-methylimidazolium chloride

c) [1,2-dmim][Cl], 1,2-dimethylimidazolium chloride

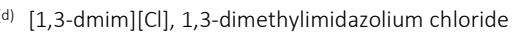

(e) [emim] [Cl], 1-ethyl-3-methyli midazolium chloride

[bmim] [Cl], 1-butyl-3-methylimidazolium chloride

(g) $[\mathrm{hmim}][\mathrm{Cl}]$, 1-hexyl-3-methylimidazolium chloride

[omim] [Cl], 1-octyl-3-methylimidazolium chloride

(i) $[$ Demim] [Cl], 1-decyl-3-methylimidazolium chloride

[Domim] [Cl], 1-dodecyl-3-methylimidazolium chloride

(k) $\left[\right.$ emim] $\left[\mathrm{EtSO}_{4}\right]$, 1-ethyl-3-methylimidazolium ethylsulfate

[emim] $\left[\mathrm{BF}_{4}\right]$, 1-ethyl-3-methylimidazolium tetrafluoroborate

(m) $\left[\right.$ bmim] $\left[\mathrm{BF}_{4}\right]$, 1-butyl-3-methylimidazolium tetrafluoroborate 
The volumetric results $\left(V_{\Phi}^{0}, S_{V}\right.$, and $\left.E_{\Phi}^{0}\right)$ for various imidazolium-based ILs in some solvents at $298.15 \mathrm{~K}$ are tabulated in Table 2.

The value of apparent molar volume at infinite dilution, $V_{\Phi}^{0}$ shows us the solute-solvent interaction (ion solvation). Meanwhile, Masson's interaction coefficient, $S_{V}$, gives valuable information about solute-solute interactions in solution; its negative values indicates weak and positive values strong solute-solute interactions. As can be seen from Table 2, values of $V_{\Phi}^{0}$ for $[\mathrm{hmim}][\mathrm{Cl}]$ in different solvents decrease in this order: $V_{\Phi}^{0}(\mathrm{~W})>V_{\Phi}^{0}(\mathrm{EtOH})>$ $V_{\Phi}^{0}(1-\mathrm{BuOH})>V_{\Phi}^{0}(\mathrm{ACN})>V_{\Phi}^{0}(\mathrm{MeOH})>V_{\Phi}^{0}(2-\mathrm{PrOH})>$ $V_{\phi}^{0}(1-\mathrm{PrOH})$. Therefore, the strongest solvation occurs in water. From Table 2 . it is evident, that $S_{V}$ coefficients have negative values for $\left[\mathrm{C}_{2} \mathrm{OHmim}\right][\mathrm{Cl}]$ and $[\mathrm{bmim}][\mathrm{Br}]$ in water medium. ${ }^{[92,93]}$ For other systems these values are positive; the strongest solute-solute interaction is in $\mathrm{EtOH}$ for [bmim] $[\mathrm{Br}] .^{[91]}$ Futhermore, values for limiting apparent molar expansibility, $E_{\Phi}^{0}$ are positive only for water medium and negative for other solvents.

As can be seen from Figure 3, values of $V_{\Phi}^{0}$ for series of imidazolium chloride ILs in water ${ }^{[22]}$ increase with the increasing of temperature. From Figure 4 it is evident that $S_{V}$ decrease with the increasing temperature and all systems indicate weaker solute-solute interactions with temperature, except in aqueous solutions of [omim] [Cl], where the interactions seem to be strengthening with temperature.

Variation of $V_{\Phi}^{0}, S_{V}$, and $E_{\Phi}^{0}$ with temperature for aqueous solutions of 1-(2-hydroxylethyl)-3-methylimidazolium chloride $\mathrm{IL}^{[92]}$ are given on Figures 5 a, b, c. From these figures, it is evident that $V_{\Phi}^{0}$ increase with temperature, while values for $S_{V}$ and $E_{\Phi}^{0}$ decrease with temperature. Namely, one of the widely used indicators of

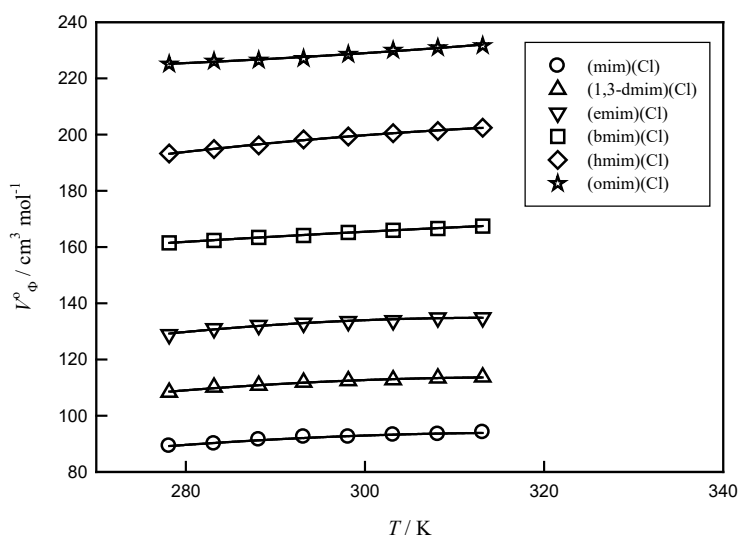

Figure 3. Temperature dependence of apparent molar volume at infinite dilution, $V_{\Phi}^{0}$ for different imidazolium chloride ILs in water medium. [22]
Table 2. The apparent molar volume at infinite dilution, $V_{\Phi}^{0}$ and interaction coefficient (or Debye-Hückel limiting slope), $S_{V}$ at $298.15 \mathrm{~K}$, and the limiting apparent molar expansibility, $E_{\Phi}^{0}$ for various imidazolium-based ILs in different solvents

\begin{tabular}{|c|c|c|c|c|}
\hline Solvent & $V_{\Phi}^{0} / \mathrm{cm}^{3} \mathrm{~mol}^{-1}$ & $S_{V} / \mathrm{cm}^{9 / 2} \mathrm{~mol}^{-3 / 2}$ & $E_{\phi}^{0} / \mathrm{cm}^{3} \mathrm{~mol}^{-1} \mathrm{~K}^{-1}$ & Ref. \\
\hline \multirow[t]{17}{*}{ W } & $194.611^{(a)}$ & $-^{\text {(a) }}$ & $0.1798^{(a)}$ & [83] \\
\hline & $162.41^{(\mathrm{b})}$ & $5.99^{(b)}$ & $0.2029^{(b)}$ & [89] \\
\hline & $180.35^{(c)}$ & $5.91^{(c)}$ & $0.1380^{(c)}$ & [89] \\
\hline & $211.26^{(d)}$ & $5.91^{(d)}$ & $0.1539^{(d)}$ & [89] \\
\hline & $173.75^{(\mathrm{e})}$ & -(e) $^{-1}$ & $4.809^{(\mathrm{e})}$ & [90] \\
\hline & $204.28^{(f)}$ & $-^{(\mathrm{f})}$ & $5.297^{(f)}$ & [90] \\
\hline & $242.91^{(\mathrm{g})}$ & _(g) & $6.106^{(\mathrm{g})}$ & [90] \\
\hline & $285.66^{(h)}$ & $-(\mathrm{h})$ & $4.652^{(\mathrm{h})}$ & [90] \\
\hline & $336.87^{(i)}$ & $-^{(i)}$ & $8.572^{(i)}$ & [90] \\
\hline & $235.79^{(j)}$ & -(j) $^{(j)}$ & $5.414^{(j)}$ & [90] \\
\hline & $261.45^{(k)}$ & $-(k)$ & $4.186^{(k)}$ & [90] \\
\hline & $296.52^{(1)}$ & $-(1)$ & $5.155^{(1)}$ & [90] \\
\hline & $381.97^{(\mathrm{m})}$ & $-_{(\mathrm{m})}$ & $9.357^{(\mathrm{m})}$ & [90] \\
\hline & $159.40^{(n)}$ & $-^{(\mathrm{n})}$ & $0.161^{(n)}$ & [91] \\
\hline & $197.70^{(0)}$ & $-(0)$ & $0.136^{(0)}$ & [91] \\
\hline & $144.56^{(p)}$ & $-79.18^{(p)}$ & $0.228^{(p)}$ & [92] \\
\hline & $170.86^{(r)}$ & $-2.6727^{(r)}$ & $0.1432^{(r)}$ & [93] \\
\hline \multirow[t]{3}{*}{$\mathrm{MeOH}$} & $156.279^{(a)}$ & - (a) & $-0.1965^{(a)}$ & [83] \\
\hline & $165.25^{(q)}$ & $15.94^{(q)}$ & $-(\mathrm{q})$ & [25] \\
\hline & $142.72^{(\mathrm{r})}$ & $18.4839^{(r)}$ & $-0.0537^{(\mathrm{r})}$ & [91] \\
\hline \multirow[t]{2}{*}{$\mathrm{EtOH}$} & $170.365^{(a)}$ & $-^{\text {(a) }}$ & $-0.2096^{(a)}$ & [83] \\
\hline & $141.23^{(r)}$ & $50.8591^{(r)}$ & $-0.0770^{(r)}$ & [91] \\
\hline 1-PrOH & $148.050^{(a)}$ & - (a) & $-0.1541^{(\mathrm{a})}$ & [83] \\
\hline 2-PrOH & $152.244^{(\mathrm{a})}$ & $--^{(a)}$ & $-0.2547^{(\mathrm{a})}$ & [83] \\
\hline 1-BuOH & $164.225^{(\mathrm{a})}$ & - (a) & $-0.1385^{\text {(a) }}$ & [83] \\
\hline \multirow[t]{2}{*}{$\mathrm{ACN}$} & $162.131^{(\mathrm{a})}$ & $-(\mathrm{a})$ & $-0.2110^{(a)}$ & [83] \\
\hline & $164.29^{(q)}$ & $12.62^{(\mathrm{q})}$ & - (q) & [25] \\
\hline DMAC & $171.78^{(a)}$ & $7.23^{(q)}$ & $-(\mathrm{q})$ & [25] \\
\hline DMSO & $183.34^{(q)}$ & $4.83^{(a)}$ & $-(q)$ & [25] \\
\hline
\end{tabular}

(a) $[\mathrm{hmim}][\mathrm{Cl}]$

(b) [1-m-3-3-bim] [Br], 1-methyl-3-(3-butenyl)imidazolium bromide

(c) [1-e-3-3-bim] [Br], 1-ethyl-3-(3-butenyl)imidazolium bromide

(d) [1-b-3-3-bim][Br], 1-butyl-3-(3-butenyl)imidazolium bromide

(e) [1,3-deim][Br], 1,3-diethylimidazolium bromide

(f) [ebim][Br], 1-ethyl-3-butylimidazolium bromide

(g) [ehim] [Br], 1-ethyl-3-hexylimidazolium bromide

(h) [eoim] [Br], 1-ethyl-3-octylimidazolium bromide

(i) [edoim] [Br]1-ethyl-3-dodecylimidazolium bromide

(j) [1,3-dbim][Br]1,3-dibutylimidazolium bromide

(k) [bhim][Br], 1-butyl-3-hexylimidazolium bromide

(I) [boim][Br],1-butyl-3-octylimidazolium bromide

(m) [bdoim][Br], 1-butyl-3-dodecylimidazolium bromide

(n) $[\mathrm{mim}]\left[\mathrm{MeSO}_{4}\right], 1,3$-dimethylimidazolium methyl sulfate

(o) $\left[\right.$ emim] $\left[\mathrm{EtSO}_{4}\right]$, 1-ethyl-3-methylimidazolium ethyl sulfate

(p) $\left[\mathrm{C}_{2} \mathrm{OHmim}\right][\mathrm{Cl}], 1$-(2-hydroxylethyl)-3-methylimidazolium chloride

(a) $\left[\right.$ bmim] $\left[\mathrm{BF}_{4}\right]$, 1-butyl-3-methylimidazolium tetrafluoroborate

(r) $[$ bmim $][\mathrm{Br}]$, 1-butyl-3-metylimidazolium bromide

IL structure making or structure breaking properties is the $E_{\phi}^{0}$. These positive values in the whole temperature range indicates structure making properties for 1-(2-hydroxylethyl)-3-methylimidazolium chloride and water solutions. 


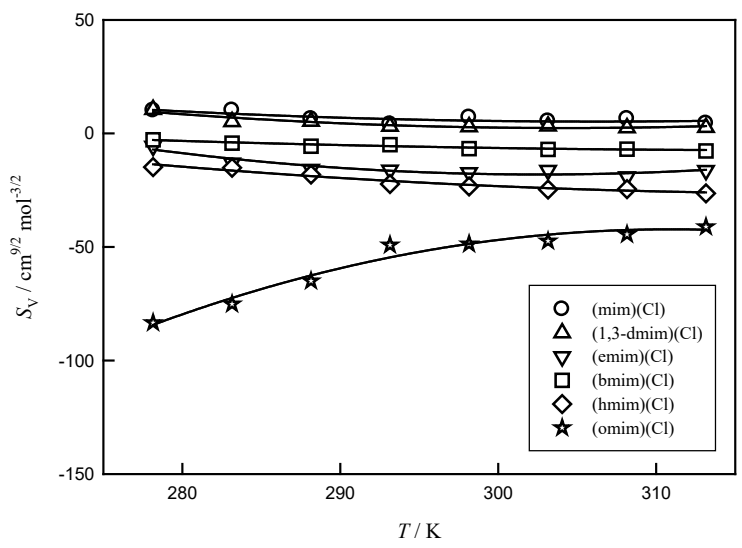

Figure 4. Temperature dependence of Masson's interaction coefficient, $S_{V}$ for different imidazolium chloride ILs in water medium. [22]
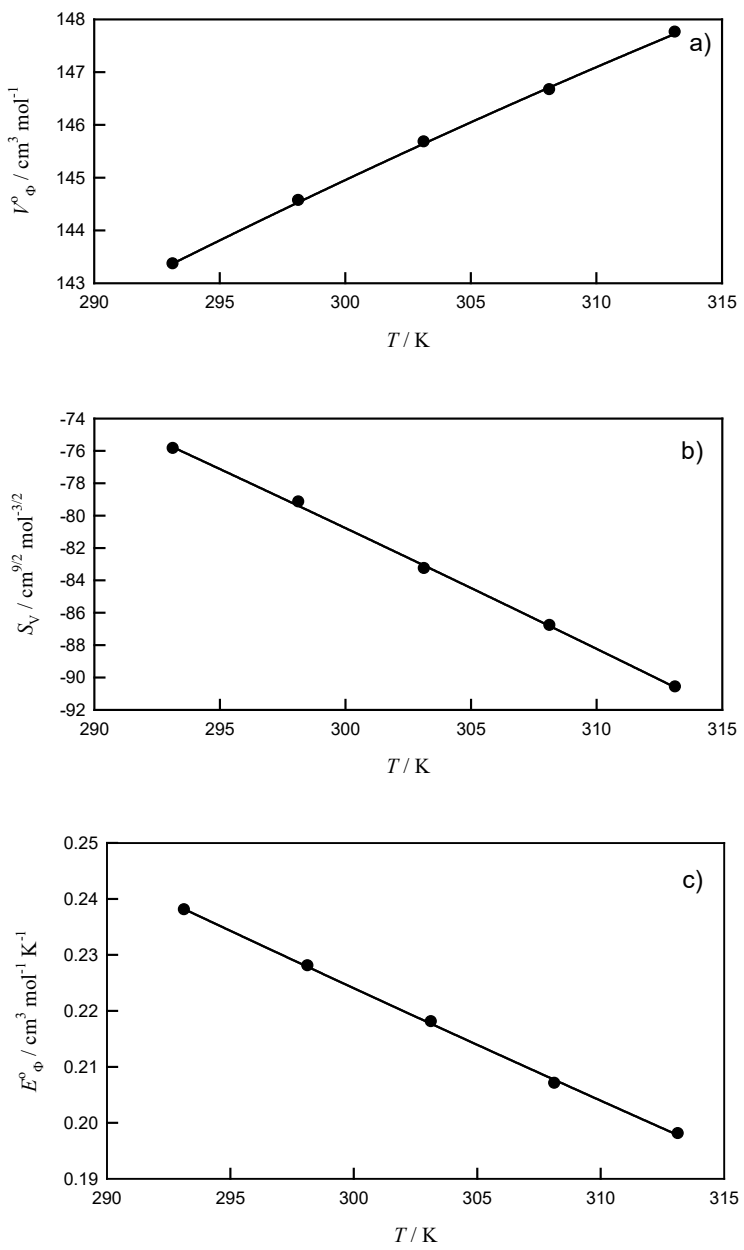

Figure 5. Temperature dependence of a) apparent molar volume at infinite dilution, $V_{\Phi}^{0}$, b) Masson's interaction coefficient, $S_{V}$, and $c$ ) limiting apparent molar expansibility, $E_{\Phi}^{0}$ for 1-(2-hydroxylethyl)-3-methylimidazolium chloride IL in water medium. ${ }^{[92]}$
Finally, positive values of viscosity $B$-coefficient also indicate strong interaction between solutes and solvents, i.e structure-making effect. Better critera to describe structure-making or structure-breaking tendency in the system is variation of the $B$-coefficients with temperature, named $\mathrm{d} B / \mathrm{d} T$ (see Figure 6 and Figure 7). From Figures 6 and 7 it is evident that viscosity $B$-coefficients for all imidazolium chloride ILs[ ${ }^{[2]}$ and different oxygen functionalized imidazolium chloride ILs ${ }^{[94]}$ show the trend of a decrease with temperature which can be attributed to a structure making nature of these ILs. Also, the effect of alkyl chain length in imidazolium ion shows that longer alkyl chain pronounced hydrophobic solvation, which leads to better structuring of water molecules around an alkyl group.

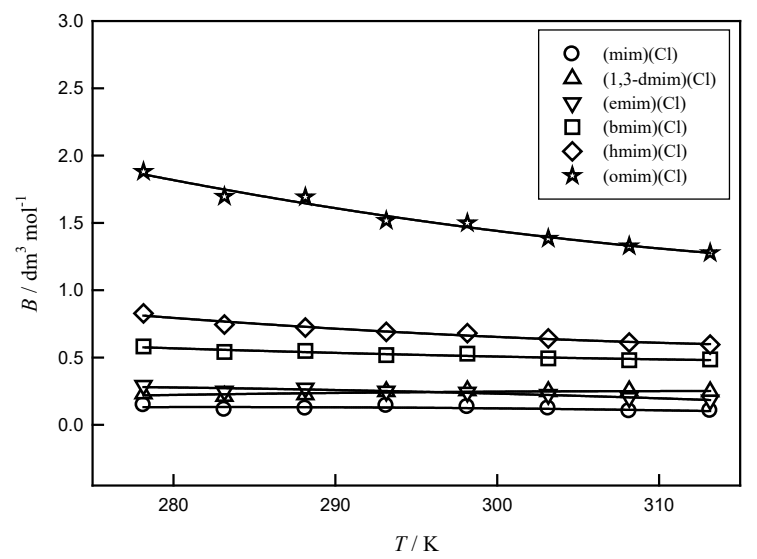

Figure 6. Temperature dependence of viscosity B-coefficient for different imidazolium chloride ILs in water medium. [22]

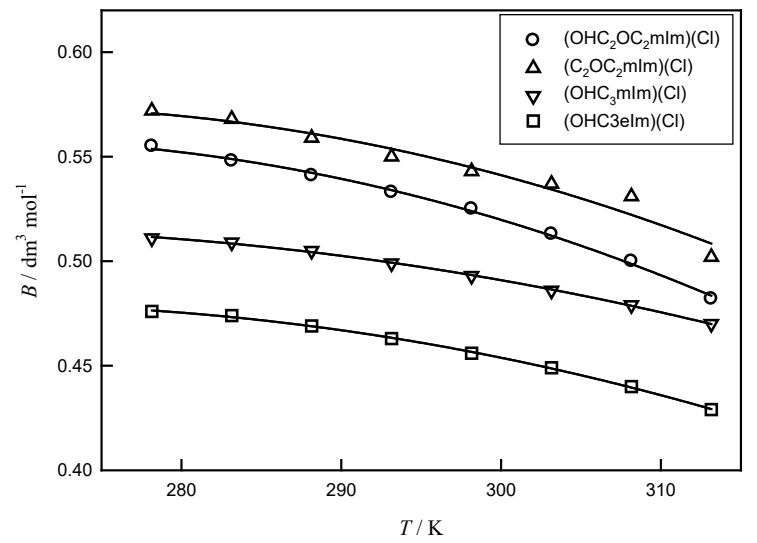

Figure 7. Temperature dependence of viscosity B-coefficient for different oxygen functionalized imidazolium chloride ILs: ([OHC $3 \mathrm{mlm}][\mathrm{Cl}]$, 1-(3-hydroxypropyl)-3-methylimidazolium chloride; $\left[\mathrm{OHC}_{3} \mathrm{elm}\right][\mathrm{Cl}]$, 1-(3-hydroxypropyl)-3-ethylimidazolium chloride; $\left[\mathrm{C}_{2} \mathrm{OC}_{2} \mathrm{mlm}\right][\mathrm{Cl}], 1$-(2-oxobutyl)-3-methylimidazolium chloride; $\left[\mathrm{OHC}_{2} \mathrm{OC}_{2} \mathrm{mlm}\right][\mathrm{Cl}], 1$-(4-hydroxy-2oxobutyl)-3-metylimidazolium chloride in water. ${ }^{[94]}$ 


\section{CONCLUSIONS}

Some experimental methods focusing on conductometry, densitometry and viscometry, and applications of imidazolium-based ILs are presented in this paper. In addition, some recent results for different imidazoliumbased ILs in various solvents media are presented. The ILs displayed in this paper, are strongly associated in DCM, 1$\mathrm{PrOH}, 2-\mathrm{PrOH}, 1-\mathrm{BuOH}$; moderate ionic association occurs in $\mathrm{MeOH}$, and slight association occurs in ACN, DCM, DMAC and DMSO; ion pairing is negligible in water. The values of viscosity $B$-coefficient and $V_{\Phi}^{0}, S_{V}$, and $E_{\Phi}^{0}$ also depend on the structure and properties of solvent and solute (ILS), and on temperature. Namely, these data are highly influenced by structure of ILs, e.g. from the alkyl chain length on the imidazolium cation. Some ILs show structure making or structure breaking tendency. According to experimental results hydrophobic hydration of the side chain on the imidazolium ring is most responsible for structure making or breaking properties of ILs. In order to expand knowledge about various molecular interactions in the IL-solvent system ${ }^{[19]}$ future studies should extend research on ILs to other molecular solvents, like calixarene-based ionic liquids. ${ }^{[95-97]}$

Acknowledgment. The author is grateful for financial support of the Ministry of the Science and Education of Republic of Croatia.

I would like to thank my colleagues and friends, prof. dr. Zdzislaw Kinart from University of Łódź, Poland and prof. dr. Milan Vraneš from University of Novi Sad, Serbia for the exellent collaboration in the field of ionic liquids.

The author would like to acknowledge the contribution (MC member from Croatia) of the COST Action CM1206Exchange on Ionic Liquids (2016-2017).

Conflict of interset statement. No potential conflict of interest was reported by the author.

\section{REFERENCES}

[1] T. Welton, Biophy. Rev. 2018, published online.

[2] Ionic Liquids, Topics in Current Chemistry, (Ed. B. Kirchner), Springer-Verlag Berlin Heidelberg, 290, pp. 2-30, 2010.

[3] J. S. Wilkes, J. A. Levisky, R. A. Wilson, L. H. Charles, Inorg. Chem. 1982, 21, 1263-1264. https://doi.org/10.1021/ic00133a078

[4] F. Faridbad, M. R. Ganjali, P. Norouzi, S. Riahi, $\mathrm{H}$. Rashedi, Application of Room Temperature Ionic Liquids in Electrochemical Sensors and Biosensors, InTech, 29, pp.643-658, 2011. https://doi.org/10.5772/14702
[5] K. R. Seddon, Kinetics and Catalysis 1996, 37, 693-697.

[6] J. H. Davis, Jr., K. J. Forrester, T. Merrigan, Tetrahedron Lett. 1998, 39, 8955-8958.

https://doi.org/10.1016/S0040-4039(98)02070-X

[7] H. Zhao, S. Xia, P. Ma, J. Chem. Technol. Biotechnol. 2005, 80, 1089-1096.

https://doi.org/10.1002/jctb.1333

[8] M. Bešter-Rogač, Acta Chim. Slov. 2020, 67, 1-14. https://doi.org/10.17344/acsi.2020.5870

[9] B. B. Gurung, M. N. Roy, Solute-Solvent Interactions in Industrially Important Solvent Media, VDM Verlag Dr. Müller, Saarbrücken, pp. 1-12, 2010.

[10] F. Scholz (Ed.), Electroanalytical Methods, SpringerVerlag Berlin, pp.280-282, 2002.

[11] K. Izutsu, Electrochemistry in Nonaqueous Solutions, Wiley-VCH Verlag GmbH, Weinheim, pp. 201-212, 2002. https://doi.org/10.1002/3527600655

[12] M. Bešter-Rogač, D. Habe, Acta Chim. Slov. 2006, 53, 391-395.

[13] Z. Kinart, J. Mol. Liq. 2017, 248, 1059-1064. https://doi.org/10.1016/j.molliq.2017.10.133

[14] J. M. G. Barthel, H. Krienke, W. Kunz, Physical Chemsitry of Electrolyte Solutions - Modern Aspects 1998, Steinkopff, Springer, Darmstadt, New York, pp. 121-130.

[15] J.-C. Justice, Electrochim. Acta 1971, 16, 701-712. https://doi.org/10.1016/0013-4686(71)85038-7

[16] E. Renard, J.-C. Justice, J. Solut. Chem. 1974, 3, 633647. https://doi.org/10.1007/BF00650407

[17] R. M. Fuoss, Proc. Natl. Acad. Sci. USA 1978, 75, 16-20.

[18] R. M. Fuoss, J. Phys. Chem. 1978, 82, 2427-2440. https://doi.org/10.1021/j100511a017

[19] R. Tomaš, Z. Kinart, M. Vraneš, Private communication 2021.

[20] Z. Kinart, R. Tomaš, Int. J. Electrochem. Sci. 2020, 15, 5560-5570. https://doi.org/10.20964/2020.06.91

[21] D. O. Masson, The London, Edinburgh, and Dublin Philosophical Magazine and Journal of Science 1929, 8, 331-342.

https://doi.org/10.1080/14786440808564880

[22] R. Tomaš, A. Tot, J. Kuhar, M. Bešter-Rogač, J. Mol. Liq. 2018, 254, 267-271.

https://doi.org/10.1016/j.molliq.2018.01.076

[23] O. Redlich, D. Meyer, Chem. Rev. 1964, 64, 221-227. https://doi.org/10.1021/cr60229a001

[24] F. J. Millero, J. Phys. Chem. 1970, 74, 356-362. https://doi.org/10.1021/j100697a022

[25] H. Shekaari, M. T. Zafarani-Moattar, Int. J. Thermophys. 2008, 29, 534-545. https://doi.org/10.1007/s10765-008-0395-z

[26] Y. Marcus, G. Hefter, Chem. Rev. 2004, 104, 34053452. https://doi.org/10.1021/cr030047d 
[27] L. G. Hepler, Can. J. Chem. 1969, 47, 4613-4617. https://doi.org/10.1139/v69-762

[28] H. Zhao, J. Chem. Technol. Biotechnol. 2006, 81, 877-891. https://doi.org/10.1002/jctb.1449

[29] G. Jones, M. Dole, J. Am. Chem. Soc. 1929, 51, 29502964. https://doi.org/10.1021/ja01385a012

[30] H. D. B. Jenkins, Y. Marcus, Chem. Rev. 1995, 95, 2695-2724.

https://doi.org/10.1021/cr00040a004

[31] R. Tomaš, T. Jovanović, M. Bešter-Rogač, Acta Chim. Slov. 2015, 62, 531-537. https://doi.org/10.17344/acsi.2015.1445

[32] M. Kaminsky, Discuss. Faraday Soc. 1957, 24, 171179. https://doi.org/10.1039/df9572400171

[33] A. Maršavelski, V. Smrečki, R. Vianello, M. Žinić, A. Moguš-Milanković, A. Šantić, Chem. Eur. J. 2015, 21, 12121-12128. https://doi.org/10.1002/chem.201500887

[34] A. Šantić, M. Brinkkötter, T. Portada, L. Frkanec, C. Cremer, M. Schönhoff, A. Moguš-Milanković, RSC Adv. 2020, 10, 17070-17078.

https://doi.org/10.1039/DORA01249A

[35] J-K. Kim, A. Matić, J-H. Ahn, P. Jacobbsson, J. Power Sources 2010, 195, 7639-7643.

https://doi.org/10.1016/j.jpowsour.2010.06.005

[36] S. Kazemiabnavi, Z. Zhang, K. Thornton, S. Banerjee, J. Phys. Chem. B 2016, 120, 5691-5702. https://doi.org/10.1021/acs.jpcb.6b03433

[37] Y. Chai, T. Xu, N. von Solms, H. Zhang, K. Thomsen, Electrochim. Acta 2020, 340, 135990. https://doi.org/10.1016/j.electacta.2020.135990

[38] E. Knipping, C. Aucher, G. Guirado, L. Aubouy, New J. Chem. 2018, 42, 4693-4699. https://doi.org/10.1039/C8NJ00449H

[39] A. Brandt, S. Pohlmann, A. Varzi, A. Balducci, S. Passerini, MRS Bulletin 2103, 38, 554-559. https://doi.org/10.1557/mrs.2013.151

[40] A. Balducci, U. Bardi, S. Caporali, M. Mastragostino, F. Soavi, Electrochem. Commun. 2004, 6, 566-570. https://doi.org/10.1557/mrs.2013.153

[41] T. Yasuda, M. Watanabe, MRS Bulletin 2013, 38, 560-566. https://doi.org/10.1557/mrs.2013.153

[42] H. Mohammed, A. Al-Othman, P. Nancarrow, Y. Elsayed, M. Tawalbeh, Int. J. Hydrog. Energy 2021, 46, 4857-4869. https://doi.org/10.1016/j.ijhydene.2019.09.118

[43] J. Xu, Z. Feng, J. Zhang, Y. Wang, IOP Conf. Series: Earth Environ. Sci. 2019, 300, 052025. https://doi.org/10.1088/1755-1315/300/5/052025

[44] F. Guo, S. Zhang, J. Wang, B. Teng, T. Zhang, M. Fan, Curr. Org. Chem. 2015, 19, 455-468. https://doi.org/10.2174/1385272819666150114235649
[45] A. J. Greer, J. Jacquemin, C. Hardacre, Molecules 2020, 25, 5207.

https://doi.org/10.3390/molecules25215207

[46] H. Zhao, Chem. Eng. Comm. 2006, 193, 1660-1677. https://doi.org/10.1080/00986440600586537

[47] M. Ramdin, T. W. de Loos, T. J. H. Vlugt, Ind. Eng. Chem. Res. 2012, 51, 8149-8177. https://doi.org/10.1021/ie3003705

[48] E. Santos, J. Albo, A. Irabien, J. Membr. Sci. 2014, 452, 277-283. https://doi.org/10.1016/j.memsci.2013.10.024

[49] A. S. Aquino, F. L. Bernard, M. O. Vieira, J. V. Borges, M. F. Rojas, F. D. Vecchia, R. A. Ligabue, M. Seferin, S. Menezesd, S. Einloft, J. Braz. Chem. Soc. 2014, 25, 2251-2257.

[50] C. Wang, H. Luo, X. Luo, H. Li, S. Dai, Green Chem. 2010, 12, 2019-2023. https://doi.org/10.1039/c0gc00070a

[51] Z. Zhao, Y. Huang, Z. Zhang, W. Fei, M. Luo, Y. Zhao, J. Chem. Thermodynamics 2020, 142, 106017. https://doi.org/10.1016/j.jct.2019.106017

[52] L. Zhou, X. Shang, J. Fan, J. Wang, J. Chem. Thermodynamics 2016, 103, 292-298. https://doi.org/10.1016/j.jct.2016.08.028

[53] F. Shaahmadi, B. H. Shahraki, A. Farhadi, J. Chem. Thermodynamics 2020, 141, 105922. https://doi.org/10.1016/j.jct.2019.105922

[54] S. Babamohammadi, A. Shamiri, M. K. Aroua, Rev. Chem. Eng. 2015, 31, 383-412. https://doi.org/10.1515/revce-2014-0032

[55] C. Cadena, J. L. Anthony, J. K. Shah, T. I. Morrow, J. F. Brennecke, E. J. Maginn, J. Am. Chem. Soc. 2004, 126, 5300-5308. https://doi.org/10.1021/ja039615x

[56] X. Han, D. W. Armstrong, Acc. Chem. Res. 2007, 40, 1079-1086. https://doi.org/10.1021/ar700044y

[57] M.-E. Yue, Y.-P. Shi, J. Sep. Sci. 2006, 29, 272-276. https://doi.org/10.1002/jssc.200500292

[58] M. Moniruzzaman, K. Nakashima, N. Kamiya, M. Goto, Biochem. Eng. J. 2010, 48, 295-314. https://doi.org/10.1016/j.bej.2009.10.002

[59] S. Tang, G. A. Baker, H. Zhao, Chem. Soc. Rev. 2012, 42, 4030-4066. https://doi.org/10.1039/c2cs15362a

[60] H. Zhao, J. Chem. Technol. Biotechnol. 2010, 85, 891-907. https://doi.org/10.1002/jctb.2375

[61] Z. S. Qureshi, K. M. Deshmukh, B. M. Bhanage, Clean Techn. Environ. Policy 2013, published online.

[62] J. K. Singh, R. K. Sharma, P. Ghosh, A. Kumar, M. L. Khan, Front. Chem. 2018, 6:548. https://doi.org/10.3389/fchem.2018.00548

[63] M. Khraisheh, F. AlMomani, M. Inamdar, M. K. Hassan, M. A. Al-Ghouti, J. Mol. Liq. 2021, 337, 116421.

https://doi.org/10.1016/j.molliq.2021.116421 
[64] M. A. Deyab, Q. Mohsen, Sci. Reports 2021, 11, 16832. https://doi.org/10.1038/s41598-021-00925-z

[65] A. F. Cristino, D. Logan, J. C. Bordado, R. G. dos Santos, Processes 2021, 9, 1214. https://doi.org/10.3390/pr9071214

[66] C. Iuga, C. Solís, J. R. Alvarez-Idabay, M. Ángel Martinez, Ma A. Mondragón, A. Vivier-Bunge, J. Mol. Model. 2014, 20, 2186.

https://doi.org/10.1007/s00894-014-2186-8

[67] B. G. Soares, S. Livi, J. Ducket-Rumean, J.-F. Gerard, Macromol. Mater Eng. 2011, 296, 826-834. https://doi.org/10.1002/mame.201000388

[68] A. Getsis, S. Tang, A.-V. Mudrig, Eur. J. Inorg. Chem. 2010, 2172-2177. https://doi.org/10.1002/ejic.200901220

[69] A. Tot, M. Vraneš, I. Maksimović, M. Putnik-Delić, M. Dančić, S. Gadžurić, S. Belić, Ecotoxicol. Environ. Saf. 2017, 147, 401-406. https://doi.org/10.1016/j.ecoenv.2017.08.066

[70] M. Matzke, S. Stolte, J. Arning, U. Uebers, J. Filser, Ecotoxicology 2008, 18, 197-203. https://doi.org/10.1007/s10646-008-0272-3

[71] L. Me, Q. Lin, Y. Song, B. Zhao, M. Fan, Open Life Sci. 2020, 15, 466-475. https://doi.org/10.1515/biol-2020-0051

[72] R. Biczak, B. Pawlowska, A. Telesinski, J. Kapusniak, Environ. Sci. Pollut. Res. 2017, 24, 18444-18457.

[73] A. Dimitrijević, T. Trtić-Petrović, M. Vraneš, S. Papović, A. Tot, S. Dožić, S. Gadžurić, J. Chem. Eng. Data 2016, 61, 549-555. https://doi.org/10.1021/acs.jced.5b00697

[74] A. Dimitrijević, Lj. Ignjatović, A. Tot, M. Vraneš, N. Zec, S. Gadžurić, T. Trtić-Petrović, J. Mol. Liq. 2017, $243,646-653$. https://doi.org/10.1016/j.molliq.2017.08.077

[75] A. Borun, J. Mol. Liq. 2019, 276, 214-224. https://doi.org/10.1016/j.molliq.2018.11.140

[76] M. Bešter-Rogač, M. V. Fedotova, S. E. Kruchinin, M. Klähn, Phys. Chem. Chem. Phys. 2016, 18, 28594-28605. https://doi.org/10.1039/C6CP05010G

[77] M. Bešter-Rogač, J. Hunger, A. Stoppa, R. Buchner, J. Chem. Eng. Data 2011, 56, 1261-1267. https://doi.org/10.1021/je101130e

[78] A. Borun, C. Fernandez, A. Bald, Int. J. Electrochem. Sci. 2015, 10, 2120-2129.

[79] M. Bešter-Rogač, A. Stoppa, J. Hunger, G. Hefter, R. Buchner, Phys. Chem. Chem. Phys. 2011, 13, 1758817598. https://doi.org/10.1039/c1cp21371g
[80] M. Bešter-Rogač, A. Stoppa, R. Buchner, J. Phys. Chem. B 2014, 118, 1426-1435. https://doi.org/10.1021/jp412344a

[81] A. Borun, A. Bald, Ionics 2016, 22, 859-867. https://doi.org/10.1007/s11581-015-1613-x

[82] A. Borun, A. Bald, Int. J. Electrochem. Sci. 2014, 9, 2790-2804.

[83] R. Sadeghi, N. Ebrahimi, J. Phys. Chem. B 2011, 115, 13227-13240. https://doi.org/10.1021/jp2055188

[84] I. V. Voroshylova, S. R. Smaga, E. V. Lukinova, V. V. Chaban, O. N. Kalugin, J. Mol. Liq. 2015, 203, 7-15. https://doi.org/10.1016/j.molliq.2014.12.028

[85] A. Borun, A. Bald, J. Chem. Eng. Data 2012, 57, 475481. https://doi.org/10.1021/je201014c

[86] M. Bešter-Rogač, J. Hunger, A. Stoppa, R. Buchner, J. Chem. Eng. Data 2010, 55, 1799-1803. https://doi.org/10.1021/je900531b

[87] Z. Kinart, A. Ćwiklinska, Phys. Chem. Liq. 2019, 57, 779-787. https://doi.org/10.1080/00319104.2018.1520851

[88] A. Borun, A. Bald, J. Chem. Eng. Data 2016, 61, 37883793. https://doi.org/10.1021/acs.jced.6b00354

[89] M. Vraneš, S. Rackov, S. Papović, B. Pilić, J. Chem. Thermodynamics 2021, 159, 106479. https://doi.org/10.1016/j.jct.2021.106479

[90] N. Zec, M. Vraneš, M. Bešter-Rogač, T. Trtić-Petrović, A. Dimitrijević, I. Čobanov, S. Gadžurić, J. Chem. Thermodynamics 2018, 121, 72-78. https://doi.org/10.1016/j.jct.2018.02.001

[91] P. D. Patil, V. R. Shaikh, G. R. Gupta, D. G. Hundiwale, J. Solution Chem. 2019, 48, 45-60. https://doi.org/10.1007/s10953-019-00845-7

[92] M. Vraneš, A. Tot, S. Armaković, S. Armaković, S. Gadžurić, J. Chem. Thermodynamics 2016, 95, 174179. https://doi.org/10.1016/j.jct.2015.12.012

[93] M. T. Zafarani-Moattar, H. Shekaari, J. Chem. Thermodynamics 2005, 37, 1029-1035. https://doi.org/10.1016/j.jct.2005.01.009

[94] A. Tot, Č. Podlipnik, M. Bešter-Rogač, S. Gadžurić, M. Vraneš, Arab. J. Chem. 2020, 13, 1598-1611. https://doi.org/10.1016/j.arabjc.2017.12.011

[95] K. Shimojo, M. Goto, Chem. Lett. 2004, 33, 320-321. https://doi.org/10.1246/cl.2004.320

[96] V. Wintgens, L. Biczok, Z. Miskolczy, Thermochim. Acta 2011, 523, 227-231. https://doi.org/10.1016/j.tca.2011.05.030

[97] F. Yang, H. Guo, Z. Jiao, C. Li, J. Ye, J. Iran. Chem. Soc. 2012, 9, 327-332. https://doi.org/10.1007/s13738-011-0027-6 